\title{
Correction to: Advances in the automated synthesis of $6-\left[{ }^{18}\right.$ F]Fluoro-L-DOPA
}

Ângela C. B. Neves ${ }^{1}$, Ivanna Hrynchak ${ }^{1}$, Inês Fonseca ${ }^{1}$, Vítor H. P. Alves ${ }^{1}$, Mariette M. Pereira ${ }^{2}$, Amílcar Falcão ${ }^{1,3}$ and Antero J. Abrunhosa ${ }^{1 *}$

The original article can be found online at https://doi.org/10.1186/ s41181-021-00126-z.

* Correspondence: antero@pet.uc.pt ${ }^{1}$ ICNAS/CIBIT — Institute for Nuclear Sciences Applied to Health, University of Coimbra, Pólo das Ciências da Saúde, Azinhaga de Santa Comba, 3000-548 Coimbra Portugal

Full list of author information is available at the end of the article

\section{Correction to: EJNMMI Radiopharm Chem 6, 11 (2021) https://doi.org/10.1186/s41181-021-00126-z}

Following publication of the original article (Neves et al. 2021), some errors were identified in the article text:

-Page 3, Fig. 2, where it reads $\mathbf{1}$ it should read 5 and ${ }^{18} \mathrm{~F}$ should be at position 5 of the aromatic ring.

-Page 6, where it reads " $M A>96 \%$ ", it should read " $\mathrm{A}_{\mathrm{m}}>37 \mathrm{GBq} / \mu \mathrm{mol}$ "

-Page 7, where it reads " $D$ - enantiomer of $2 \%$ " it should read "D- enantiomer of $4 \%$ "

-Page 8, where it reads "using a cPTC" it should read: "using different catalysts".

-In page 8, Fig. 7, caption, where it reads "Chiral phase transfer catalysts (cPTC),", it should read "Catalysts."

-Pages 8-9, where it reads "6- ${ }^{18}$ Flfluoro-3,4-dimethoxybenzyl bromide" and "Sep-

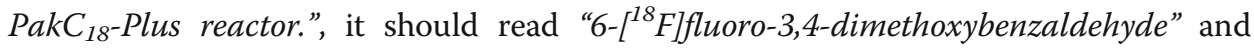
"Sep-PakC 18 -Plus", respectively.

-Page 9, Fig. 8, where it reads "22 or 23", it should read "23 or 24" and, number $\mathbf{2 4}$ under the structure, should be disregarded.

-Page 9, where it reads "Krasikova also prepared nitropiperonal 12 (Krasikova et al., 2004), using a combination of cPTC, 22." it should read "Krasikova also prepared 6$\left[{ }^{18}\right.$ F]FDOPA (Krasikova et al., 2004), using a combination of 22."

-Page 10, caption of Table 2, where it reads "using cPTC as alkylation agent." it should read "using different catalysts."

-Page 10, Table 2, line 1, where it reads "PTC", should read "catalyst".

-Page 12, Table 3, entry 3 , where it reads " $31 \pm 3$ ", it should read " $31 \pm 3$ ", and where it reads "n.d. not described", it should read "n.d. not described. "RCY for protected 6$\left[{ }^{18}\right.$ F]FDOPA".

-Page 13, where it reads, "6- $\left[{ }^{18} \mathrm{~F}\right] \mathrm{FDOPA}$ with $31 \pm 3 \% \mathrm{RCY}$ " it should read "the protected $6-{ }^{18}$ FJFDOPA with $31 \pm 3 \%$ RCY".

-Page 14, where it reads "described in section 2.2.", it should read "described previously".

(c) The Author(s). 2021 Open Access This article is licensed under a Creative Commons Attribution 4.0 International License, which permits use, sharing, adaptation, distribution and reproduction in any medium or format, as long as you give appropriate credit to the original author(s) and the source, provide a link to the Creative Commons licence, and indicate if changes were made. The images or other third party material in this article are included in the article's Creative Commons licence, unless indicated otherwise in a credit line to the material. If material is not included in the article's Creative Commons licence and your intended use is not permitted by statutory regulation or exceeds the permitted use, you will need to obtain permission directly from the copyright holder. To view a copy of this licence, visit http://creativecommons.org/licenses/by/4.0/. 
-Page 15, Fig. 14 where it reads "13, 14, 22 or 23", it should read "14, 15, 23 or 24" and number $\mathbf{2 4}$ under the structure should be disregarded.

-Page 15, where it reads "MA $129500 \mathrm{Gbq} / \mu \mathrm{mol}$ ", it should read "Am 129,5 GBq/ umol".

-Page 15, Fig. 15, where it reads "31, 32 and 33", it should be read "37, 38 and 39".

-Page 16, where it reads "nitroveratraldeyde 12", it should read nitroveratraldeyde 11 " and, where it reads "precursor 31" it should read precursor 37".

-There are multiple occurrences of $[18 \mathrm{~F}]$. They should read $\left[{ }^{18} \mathrm{~F}\right]$.

- MA is used throughout for Molar Activity. It should be $A_{m}$.

-The following reference is missing: Mossine A V., Tanzey SS, Brooks AF, Makaravage KJ, Ichiishi N, Miller JM, et al. One-pot synthesis of high molar activity 6[18F]fluoro-l-DOPA by Cu-mediated fluorination of a BPin precursor. Org Biomol Chem. 2019;17(38):8701-5.

The original article (Neves et al. 2021) has been corrected.

\section{Author details}

${ }^{1}$ ICNAS/CIBIT — Institute for Nuclear Sciences Applied to Health, University of Coimbra, Pólo das Ciências da Saúde, Azinhaga de Santa Comba, 3000-548 Coimbra, Portugal. ${ }^{2}$ Coimbra Chemistry Center, Chemistry Department, University of Coimbra, Rua Larga, 3004-535 Coimbra, Portugal. '²aboratory of Pharmacology, Faculty of Pharmacy, University of Coimbra, Pólo das Ciências da Saúde, Azinhaga de Santa Comba, 3000-548 Coimbra, Portugal.

Published online: 20 May 2021

Reference

Neves ÂCB, et al. Advances in the automated synthesis of 6-[ ${ }^{18}$ F]Fluoro-L-DOPA. EJNMMI Radiopharm Chem. 2021;6:11 https://doi.org/10.1186/s41181-021-00126-z. 